\title{
Idiomatic Knowledge and Attitudes toward Idiom Learning: A Case of Kuwaiti EFL College Students
}

\author{
Shorouq K. Al-Houti* $\quad$ Sultan M. Aldaihani $\quad$ Yousef M. Alenezi \\ The English Department, College of Basic Education, the Public Authority for Applied Education and Training, \\ Al-Ardhiya, Kuwait
}

\begin{abstract}
The study attempts to determine if idiomatic knowledge has an influence on students' attitudes toward learning English idioms. Primarily, the study seeks to uncover if idiomatic knowledge affects Kuwaiti EFL undergraduate college students' attitudes toward (1) the importance of idiom learning, (2) the difficulties of idiom learning and (3) learning strategies for idioms. Results showed that students had positive attitudes toward English idiom learning. Significant differences in the results were obtained for students' knowledge of idioms.
\end{abstract}

Keywords: Idiom learning, EFL students' attitudes, idiomatic knowledge

DOI: $10.7176 / \mathrm{JEP} / 12-27-09$

Publication date:September $30^{\text {th }} 2021$

\section{Introduction}

Vocabulary learning involves not only learning individual lexical items but also learning multiword expressions (i.e. idioms, collocations, phrasal verbs, proverbs etc.). Vocabulary knowledge is considered incomplete without the acquisition of multiword expressions. Idiomatic expressions give any language flavor and color (Moreno, 2011); they are central to learning a foreign/second language particularly because of the frequency with which they occur. They are pervasive in human communication, especially in spoken language. Pollio et al. (1977) estimate that "most English speakers utter about . . 7,000 idioms per week" (p. 233-234). Likewise, Strässler (1982) detects one idiom every four-and-a-half minutes of discourse in conversational data of more than 100,000 words. Due to the ubiquity of idioms, mastering a wide range of idiomatic expressions is considered to be an indicator of native-like command of the language as well as a reliable measure of proficiency and fluency (Fernando, 1996; Howarth, 1998; Oppenheim, 2000; Schmitt, 2000, Weinert, 1995; Wray, 2000; Yorio,1989). As Thiel (1979) has pointed out, "sooner or later, lack of precise idiomatic usage will betray the foreign background even of a speaker with an excellent grammatical knowledge, vocabulary, and pronunciation. And just as surely command of idiom will generate confidence and respect” (p. 23).

Different scholars have given different definitions of what constitutes an idiom. Most scholars have agreed on that the key properties of idioms are that (1) idioms are often but not always nonliteral or semiliteral; (2) they are often rigid in structure; and (3) idioms are multiword expressions. Idioms are nonliteral because their meanings cannot be completely deduced from the interpretation of their components. Bolinger (1975) defines idioms as "groups of words with set meaning that cannot be calculated by adding up the separate meaning of the parts" (p. 100). For instance, the meaning of the expression spill the beans has nothing to do with beans; rather, it indicates revealing a secret. Idioms are often rigid in structure as they allow some restricted variance or completely invariant; for example, one can say spilled the beans but not spill the bean. Additionally, the idiom kick the bucket, for instance, would lose its idiomatic sense if it underwent adjective or attributive insertion, determiner change, passivization, or relativization, while these morphosyntactic variations are acceptable for spill the beans. Most scholars consider an idiom as a multiword sequence rather than a single word (Liu, 2008; Moreno, 2011, Pitzl, 2016). That being said, Katz and Postal (1963) believe that individual words including polymorphemes can qualify as idioms and refer to them as lexical idioms. These properties and others make learning idioms a thorny issue for EFL/ESL learners.

\section{Statement of the Problem}

Due to the widespread use of idioms in daily conversations and in order to develop speech fluency, EFL/ESL learners need to learn how to use idiomatic expressions appropriately (Irujo, 1986b; Levorato, 1993; Oppenheim, 2000; Sugano, 1981), but these expressions often pose a challenge to learn (Cooper 1998, 1999; Irujo, 1986a, 1986b; Liontas, 2002; Liu, 2003; Nelson, 1992; Nippold, 2003; Steinel, Hulstijn \& Steinel 2007). In sharp contrast to the abundance of research on EFL/ESL idiom learning in general; however, studies on how Arabic learners comprehend English idioms are scant. Specifically, studies on Kuwaiti learners of English and idiom learning are particularly scant (Al-Houti \& Aldaihani, 2020). Also, the effect of idiomatic knowledge on attitudes of EFL learners remains to be addressed. Therefore, it is necessary for researchers to conduct a research on this topic. The present study serves to address this research gap and contributes to the existing literature by highlighting the effect of idiomatic knowledge on Kuwaiti EFL learners' attitudes with regards to idiom learning. 


\section{Literature Review}

\subsection{Importance of Idioms}

ESL/EFL learners should have knowledge of English idioms, as their use enables fluent and natural language production (Liontas, 1999; Prodromou, 2003; Wray, 2000; Yorio, 1980). Hence, teachers should focus on teaching idioms to help learners produce language more fluently and naturally. Idioms should be included in language curricula as learners can be at risk of misinterpreting the meaning of idioms outside of an educational context. Therefore, foreign language textbooks and materials containing figurative language are considered good sources to teach idioms to learners, which will help them improve their communicative competence (Can, 2011). Learning L2 idioms is particularly important, as these expressions are an important part of vocabulary and they are pervasive in native language (Pawley \& Syder, 1983). The common use of idioms in everyday spoken and written communication has been well-documented (Makkai et al., 1995; Milosky, 1994; Nippold, 1991; Popiel \& McRae, 1988; Pollio et al., 1977). As Viteli (1989) stated, "English is very rich in idiomatic expressions. In fact, it is difficult to speak or write English without idioms" (p. 2). Idioms are important to learn in order to achieve effective communication. This is particularly true given that idioms incorporate cultural aspects and learning them embodies learning a culture (Bachman, 1990; Glucksberg \& McGlone, 2001; Ovando \& Collier, 1985). According to Cuadros (2014), learning idioms will foster students' intercultural communicative competence. Moreover, researchers believe that a sound knowledge of idioms is inevitable for proficiency and fluency in English (Boers et al., 2006; Liu, 2008; Shirazi \& Talebinezhad, 2013; Wray, 2002). According to Cowie and Mackin (1975), one of the defining characteristics of native proficiency is idiomatic competence. In addition, Liu (2008) explains that "a decent command of a language entails a grasp of some of its basic idioms. In fact, the level of command of idioms is an important indicator of second language (L2) proficiency." (p. i).

\subsection{Difficulties of Idiom Learning}

Idioms are considered a stumbling block for ESL/EFL learners (Andreou \& Galantomos, 2007; Cooper, 1999; Irujo, 1984, 1986b; Liontas, 2002; Nippold, 2003). There are several factors which make idioms difficult to learn in a second or foreign language context. According to Irujo (1986a), ESL/EFL learners struggle with proper usage of idioms. Learners find idioms hard to use correctly in proper context. Researchers explored whether ESL/EFL learners avoid idioms (Irujo, 1993; Laufer, 2000; Yorio, 1989). Avoidance indicates a difficulty that learners may have with the avoided form. Avoidance presumes some knowledge of the avoided form, as one cannot avoid something that he/she does not know. Yorio (1989) investigated the use of idioms by ESL college students and compared it with that of native speakers of English. He analyzed written production of idioms in both groups and found that native speakers used more idiomatic expressions than L2 learners. Moreover, he found that L2 learners not only used fewer idioms in their writing, but also used idioms incorrectly. By contrast, Laufer (2000) showed that idioms were not avoided as a category but some specific idiom types were avoided. She attributed avoidance of specific idiom types to L1-L2 degrees of similarity.

Several studies have focused on the role of L1 in L2 idiom comprehension and concluded that L1 affects L2 idiom comprehension; the effects, however, are both negative and positive (Irujo 9886a; Liontas 2001, 2002b, and 2003). Irujo (1986a) conducted one of the earliest studies investigating the influence of learners' L1 on L2 idiom comprehension. Her participants were Venezuelan advanced learners of L2 English, who were attending college in the United states. In her study, the idioms used were divided into three categories based on similarity between L1 and L2: identical idioms, meaning those that are identical in form and meaning in L1 and L2; similar idioms, which have similar meaning and form in L1; and different idioms, which have no similarity to L1. The data revealed that transfer from L1 is affected by the degree of similarity of the idioms between the two languages. Identical idioms were the easiest to comprehend and produce, followed by similar idioms, which showed interference from the native language. Different idioms were the most difficult to comprehend and produce, but showed less interference from the native language. Similar results were obtained in three studies by Liontas $(2001,2002 b$, and 2003).

Another reason for the difficulty of learning idioms is related to their nonliteral meaning. Idioms are difficult to master because their meanings are unpredictable. As Cooper (1999) elucidates, "because figurative meaning is unpredictable, idioms present a special learning problem for virtually all groups of learners" (p. 233). Irujo (1986b) believes that idioms are problematic because they have nonliteral meanings, but can also have literal counterparts that might confuse learners. The degree of agreement between the literal and nonliteral meanings of idioms is called transparency (Cain et al. 2005). The higher the transparency, the easier it is to derive the meaning of the idiom. The least transparent are described as opaque. Hence, transparent idioms are easier to comprehend than opaque idioms (Cooper 1998; Gibbs 1993). Additionally, idiom familiarity is the extent to which people are said to be familiar with the meaning of the idiom (Abel, 2003; Hubers et al. 2019; Nordmann et al. 2014). Studies indicated that most familiar idioms are easier to understand than less familiar ones (Cronk \& Schweigert, 1992, 1993; Titone \& Connine, 1994).

Furthermore, idioms incorporate aspects of the larger cultural context in which the target language arose 
(Bachman, 1990). One of the main reasons that makes idioms difficult to interpret is their cultural specificity. Researchers studied the influence of etymological elaboration (Boers et al. 2007, 2008, 2009) and familiarity with culture-bound expressions (Boers et al. 2001, 2004) as ways to foster figurative language in L2. Idioms can be a source of potential misunderstanding when culture-specific knowledge is implied. Sometimes idioms reflect themes and ideas that are absent in the learner's own culture, which would hinder comprehension. Elkilic (2008) pointed out that idioms are culture-bound, and thus it is not easy to understand their meaning even if they are transparent. He further (1990) stated that "knowledge about idiomacity is not based on linguistic analysis, but it is essentially a matter of cultural awareness." (p. 31). For example, the idiom carry coals to Newcastle in British culture means to take something to a place where it is not needed. Since cross-cultural variation can have an impact on the learner's interpretation of idioms, Boer and Demecheleer (2001) suggested that the best approach to teaching idioms is to benefit from the teacher's awareness of cross-cultural differences.

\subsection{Comprehension Strategies for L2 Idioms}

The use of contextual information is one of the major strategies employed by L2 learners to comprehend idioms. Cooper (1999) identified eight major strategies that L2 learners employed when analyzing idioms: guessing from context, using literal meaning, referring to L1, and using other strategies. Guessing from context was the most frequent employed strategy, used in $28 \%$ of instances; using the literal meaning was also among the frequent strategies (19\%). However, there were individual variations across participants and within participants. Cooper (1999) explained these variations by referring to comprehension and that it is a dynamic process. Along the same lines, Bulut and Celik-Yazici (2004) conducted a study investigating idiom-processing strategies of eighteen Turkish teachers of English. The participants used a heuristic approach when they encountered unknown idioms, with guessing from context ranked as the most -used strategy. This led the researchers to hypothesize that L2 learners will first resort to contextual information to interpret idioms. In line with Cooper (1999), they also found that L2 learners do not use a single strategy but a variety of strategies as appropriate. Similarly, studies showed that learners rely on context and L1 to decode idioms (Liu, 2008; Saleh \& Zakaria, 2013). Other studies demonstrated that learners utilize keywords (Guduru, 2012) and mnemonic strategies like etymological elaboration (Boers et al., 2004).

\subsection{Attitudes and Knowledge of Idioms}

Studies on attitudes of Kuwaiti Arabic learners of English and idiom learning are exceptionally rare (Al-Houti \& Aldaihani, 2018). Al-Houti and Aldaihani (2018) investigated Kuwaiti EFL students' attitudes toward learning English idioms; the researchers examined two learner-related variables (age and year of study) and concluded that Kuwaiti EFL college students had positive attitudes toward idiom learning overall, but that the results indicated significant differences in attitudes toward English idiom for the independent variable age. Research had shown that many EFL students are handicapped in their ability to comprehend idioms and have poor idiomatic competence (Adkins, 1968; Hussein, Khanij \& Makhzoomy, 2001; Katsarou, 2011). A very small number of studies have been devoted to Arabic EFL/ESL learners and idiomatic knowledge (Aljabri, 2013; AlKhawaldeh et al., 2016; Al-Kadi, 2015). Al-Houti and Aldaihani (2020) conducted the sole existing study that tested Kuwaiti EFL learners' knowledge of frequently used English idioms. The results showed that these learners have difficulty comprehending common idiomatic expressions. The relationship between idiomatic competence of EFL learners and their perceptions of idiom learning is seldom investigated in the literature. Tran (2013) explored this relationship by examining university students in Vietnam; the results revealed that students had poor idiomatic competence while, more interestingly, uncovering a paradox between learners' idiomatic knowledge and their desire to learn idioms.

Due to a paucity of research on the subject, the purpose of this study is to examine the effect of idiomatic knowledge on students' attitudes toward idiom learning. The research questions of the present study are:

1. Do EFL college students' attitudes toward idiom learning differ based on their preexisting knowledge of idioms?

2. Do EFL college students with different levels of idiomatic knowledge differ in their attitudes toward the importance of idioms, the difficulties of idioms, and idiom-learning strategies?

3. Do EFL college students with different levels of idiomatic knowledge differ in their attitudes toward the individual survey items?

\section{Methods}

\subsection{Participants}

A total of 218 female EFL undergraduate students participated in the study. The participants were English major students at the CBE (College of Basic Education) in Kuwait. All of the participants who took part in the study were native speakers of Arabic. Their age ranged between 18 and 41 years old. They were chosen randomly to participate in the study. 


\subsection{Instruments}

An idiomatic knowledge test, consisting of 27 frequently used idioms, was designed to assess the students' knowledge of frequently used idioms. The selection of idioms was based on several criteria: (1) idioms from among the 300 most common English idioms, according to the frequency analysis of Collins COBUILD data, (2) idioms that can be used in both British and American English, (3) idioms covering various structural patterns, (4) idioms covering the spectrum of idiomaticity, and (5) idioms that have equivalents in Arabic (identical or similar) as well as those that lack Arabic equivalents. The designed test consisted of matching, multiple-choice, and gapfill tasks. The matching task requires the participants to match the meanings and the idioms. The multiple-choice task requires selecting the most appropriate idiom for each situation. The gap-fill task requires completing the idioms based on meaning.

To measure students' attitudes toward learning English idioms, the researchers created a questionnaire to fulfil this purpose after an exhaustive review of relevant studies (see, e.g., Cooper, 1999; Guduru, 2012; Irujo 1986; Khan \& Can Daşkin, 2014; Liu, 2008; Pimenova, 2011; Saleh \& Zakaria, 2013; Tran, 2013). The questionnaire consisted of 19 items with a five-point Likert scale $(1=$ strongly disagree, $2=$ disagree, $3=$ neutral, 4 agree, and $5=$ strongly agree). The 19 items consisted of three subscales of students' attitudes toward learning English idioms: (1) attitudes toward importance of English idiom learning, (2) attitudes toward difficulties of English idiom learning, and (3) attitudes toward learning strategies of idioms. Table 1 presents the questionnaire items and their corresponding subscales.

\section{Table 1}

Questionnaire Items

\begin{tabular}{|c|c|c|}
\hline Subscale & No. & Statement \\
\hline \multirow{8}{*}{$\begin{array}{l}\text { Importance of } \\
\text { Idioms }\end{array}$} & Q1 & Idioms are very important for English language learners. \\
\hline & Q2 & English language learners should have knowledge about idioms. \\
\hline & Q3 & English language teachers should teach students idioms. \\
\hline & Q4 & Idioms should be included in language curricula. \\
\hline & Q5 & Idioms are important because they are frequent and common. \\
\hline & Q6 & $\begin{array}{l}\text { Idioms are important because they can communicate aspects in a nonliteral (figurative) } \\
\text { way. }\end{array}$ \\
\hline & Q7 & Idioms are important because they reflect and represent culture. \\
\hline & Q8 & $\begin{array}{l}\text { Idioms are important because they indicate native-like knowledge of the language as } \\
\text { they reflect proficiency. }\end{array}$ \\
\hline \multirow{6}{*}{$\begin{array}{l}\text { Difficulties of } \\
\text { Idiom Learning }\end{array}$} & Q9 & Idioms are difficult. \\
\hline & Q10 & $\begin{array}{l}\text { Idioms are difficult because they are not frequent and familiar (frequency and } \\
\text { familiarity). }\end{array}$ \\
\hline & Q11 & $\begin{array}{l}\text { Idioms are difficult because they are nonliteral (figurative) so the meaning of the idiom } \\
\text { is not the meaning of its constituent words. }\end{array}$ \\
\hline & Q12 & Idioms are difficult because they are hard to use in contexts. \\
\hline & Q13 & Idioms are difficult because some do not have L1 equivalents. \\
\hline & Q14 & Idioms are difficult because they require cultural and historical knowledge. \\
\hline \multirow{5}{*}{$\begin{array}{l}\text { Learning } \\
\text { Strategies for } \\
\text { Idioms }\end{array}$} & Q15 & I rely on L1 to learn idioms, i.e. through L1 translation. \\
\hline & Q16 & $\begin{array}{l}\text { I use contextualization to learn idioms, i.e. through contexts (written, videographic, } \\
\text { etc.). }\end{array}$ \\
\hline & Q17 & I use etymological explanations to learn idioms (mnemonic strategy). \\
\hline & Q18 & I use descriptive definitions in English to learn idioms (meaning in L2). \\
\hline & Q19 & I use key words to learn idioms. \\
\hline
\end{tabular}

\subsection{Procedure}

To establish the validity of the idiomatic knowledge test, specialists in the English language and literature department were asked to review it. They judged the selected idioms as highly familiar. A pilot study was conducted on 35 female EFL undergraduate students (who were excluded from the main study) to verify the reliability and validity of the instrument. The researchers administered the test to measure the students' idiomatic knowledge. The students took the test in a quiet classroom at CBE. Students were asked to complete the test at their own pace. A Cronbach's alpha reliability coefficient of 0.77 was calculated, suggesting that reliability of the instrument was satisfactory.

As to the questionnaire, it was also piloted with a small group of EFL undergraduate students to check the clarity of the items before the actual implementation, as well as to verify the reliability and validity of the instrument. As a result, some modifications were made to improve the questionnaire. The revised version of the 
questionnaire was distributed along with the idiomatic knowledge test. Hence, participants who took the idiomatic knowledge test also completed the questionnaire. A Cronbach's alpha was above .70, suggesting that reliability of the instrument was satisfactory. All subjects gave informed consent to participate in the study, and ethical approval was obtained.

\section{Data Analysis}

The questionnaire items contained three subscales of students' attitudes toward learning English idioms. For each subscale, a composite score was created by averaging the responses of the corresponding survey items. The composite scores ranged from 1 to 5 , with higher scores indicating more positive attitudes toward the subscale. Normality of the data was assessed via the Shapiro-Wilk test. A $p$-value $<0.05$ on the Shapiro-Wilk test indicated that data were not normally distributed. Kruskal-Wallis tests (Hollander and Wolfe, 1999) were used to determine if there was a statistically significant difference in the 1) three subscales of EFL college students' attitudes toward learning English idioms, and 2) the responses to each individual survey item among participants with different knowledge of idioms. If the results of Kruskal-Wallis test were significant, Dunn's procedure (Dunn, 1964) for pairwise comparisons was performed. For the tests, $p$-values less than 0.05 indicated significance. All analyses were conducted using SPSS version 23 (IBM Corp., Armonk, NY).

\section{Results and Discussion}

The research question of the present study asked: Do EFL college students' attitudes differ based on their knowledge of idioms? To answer this research question, Kruskal-Wallis tests were used to determine if there was a statistically significant difference in the 1) three subscales of EFL college students' attitudes toward learning English idioms, and 2) the responses to each individual survey item among participants with different knowledge of idioms.

6.1 Results of the three subscales according to knowledge of idioms

The results of the Kruskal-Wallis tests for the three subscales are presented in Table 2.

Table 2

Results of the Kruskal-Wallis Tests for the Three Subscales

\begin{tabular}{lcccc}
\hline \multicolumn{5}{c}{ Knowledge of idioms } \\
\hline & $0-6(N=32)$ & $7-13(N=129)$ & $14-27(N=57)$ & $p$ \\
Importance & $3.98(0.43)$ & $4.02(0.54)$ & $4.20(0.42)$ & 0.050 \\
Difficulties & $3.51(0.67)$ & $3.26(0.78)$ & $3.12(0.64)$ & $0.042^{*}$ \\
Learning strategies & $3.66(0.45)$ & $3.59(0.61)$ & $3.39(0.59)$ & $0.031^{*}$ \\
\hline
\end{tabular}

Note: Importance $=$ Attitudes toward importance of English idiom learning, Difficulties $=$ Attitudes toward difficulties of English idiom learning, Learning strategies = Attitudes toward learning strategies of idioms. Numbers in parentheses are standard deviation. $p=p$-values based on Kruskal-Wallis tests. * indicates significance.

There was a statistically significant difference in attitudes toward difficulties of English idiom learning among participants with different knowledge of idioms $(p=0.042)$. In particular, the results of the pairwise comparisons indicated that people with the lowest marks (0-6) had statistically significantly more positive attitudes toward the difficulties of English idiom-learning than people with the highest marks (14-27) $(M=3.51$ for $0-6, M=3.12$ for $14-27, p=0.037)$; there was no statistically significant difference in attitudes toward the difficulties of English idiom-learning between knowledge of idioms $0-6$ and 7-13 $(p=0.330)$, and between knowledge of idioms 7-13 and 14-27 $(p=0.410)$.

There was a statistically significant difference in attitudes toward learning strategies for idioms among participants with different knowledge of idioms $(p=0.031)$. However, the results of the pairwise comparisons indicated that there was no statistically significant difference in attitudes toward learning strategies for idioms among participants with different knowledge of idioms ( $p=0.055$ for $14-27$ vs. $7-13 ; p=0.084$ for $14-27$ vs. $0-6 ; p=1.000$ for $7-13$ vs. $0-6)$. Thus, we concluded that there was no statistically significant difference in attitudes toward learning strategies for idioms among participants with different knowledge of idioms.

There was no statistically significant difference in attitudes toward importance of idioms among participants with different knowledge of idioms $(p=0.050)$.

6.2 Results of the individual survey items according to knowledge of idioms

The results of the Kruskal-Wallis tests for the individual survey items are presented in Table 3. 
Table 3

Results of the Kruskal-Wallis tests for the Survey Items

\begin{tabular}{|c|c|c|c|c|}
\hline & \multicolumn{3}{|c|}{ Knowledge of Idioms } & \multirow[b]{2}{*}{$p$} \\
\hline & $\begin{array}{l}0-6(N= \\
32)\end{array}$ & $\begin{array}{l}7-13(N= \\
129)\end{array}$ & $14-27(N=57)$ & \\
\hline Q1 & $4.25(0.72)$ & $4.19(0.74)$ & $4.28(0.75)$ & 0.724 \\
\hline Q2 & $4.22(0.71)$ & $4.36(0.75)$ & $4.61(0.53)$ & $0.018 *$ \\
\hline Q3 & $3.88(0.79)$ & $3.92(0.87)$ & $4.07(0.53)$ & 0.493 \\
\hline Q4 & $3.66(1.04)$ & $3.53(0.99)$ & $3.74(0.79)$ & 0.437 \\
\hline Q5 & $4.06(0.84)$ & $4.02(0.79)$ & $4.19(0.64)$ & 0.471 \\
\hline Q6 & $4.13(0.94)$ & $4.19(0.80)$ & $4.44(0.66)$ & 0.119 \\
\hline Q7 & $3.81(0.97)$ & $3.95(0.98)$ & $4.11(0.90)$ & 0.371 \\
\hline Q8 & $3.88(0.87)$ & $4.00(0.98)$ & $4.14(0.85)$ & 0.360 \\
\hline Q9 & $3.19(1.00)$ & $2.81(1.01)$ & $2.63(0.84)$ & 0.065 \\
\hline Q10 & $3.25(1.24)$ & $3.10(1.10)$ & $3.00(0.87)$ & 0.547 \\
\hline Q11 & $3.88(1.04)$ & $3.53(1.08)$ & $3.47(0.93)$ & 0.160 \\
\hline Q12 & $3.34(0.97)$ & $3.16(1.10)$ & $2.65(0.95)$ & $0.002 *$ \\
\hline Q13 & $3.72(1.08)$ & $3.64(1.14)$ & $3.54(0.85)$ & 0.408 \\
\hline Q14 & $3.66(0.94)$ & $3.34(1.08)$ & $3.40(0.94)$ & 0.225 \\
\hline Q15 & $3.72(1.11)$ & $3.16(1.14)$ & $2.61(1.18)$ & $0.000 *$ \\
\hline Q16 & $3.91(0.93)$ & $3.91(0.96)$ & $3.93(0.88)$ & 0.999 \\
\hline Q17 & $2.91(1.09)$ & $3.16(1.18)$ & $3.04(1.00)$ & 0.424 \\
\hline Q18 & $3.72(0.77)$ & $3.78(0.94)$ & $3.68(1.04)$ & 0.824 \\
\hline Q19 & $4.03(0.90)$ & $3.92(0.83)$ & $3.70(0.98)$ & 0.189 \\
\hline
\end{tabular}

Numbers in parentheses are standard deviation. $p=p$-values based on Kruskal-Wallis tests. * indicates significance at the 0.05 level.

Table 4

Cumulative Percent for Survey Items

\begin{tabular}{lcccc}
\hline No. & \multicolumn{3}{c}{ Knowledge of Idioms } \\
\hline & \%Agree & \%Agree & $\%$ Agree & \%Agree (Total) \\
Q1 & $(0-6)$ & $(7-13)$ & $(14-27)$ & $86.7 \%$ \\
Q2 & $90.6 \%$ & $87.6 \%$ & $82.5 \%$ & $93.1 \%$ \\
Q3 & $90.6 \%$ & $91.5 \%$ & $98.2 \%$ & $72.9 \%$ \\
Q4 & $68.8 \%$ & $72.1 \%$ & $77.2 \%$ & $56 \%$ \\
Q5 & $56.3 \%$ & $52.7 \%$ & $63.2 \%$ & $83 \%$ \\
Q6 & $81.3 \%$ & $81.4 \%$ & $87.7 \%$ & $84.4 \%$ \\
Q7 & $84.4 \%$ & $45.7 \%$ & $91.2 \%$ & $75.2 \%$ \\
Q8 & $81.3 \%$ & $73.6 \%$ & $75.4 \%$ & $74.8 \%$ \\
Q9 & $68.8 \%$ & $73.6 \%$ & $80.7 \%$ & $23.4 \%$ \\
Q10 & $34.4 \%$ & $24 \%$ & $15.8 \%$ & $39 \%$ \\
Q11 & $46.9 \%$ & $41.1 \%$ & $29.8 \%$ & $59.6 \%$ \\
Q12 & $65.6 \%$ & $60.5 \%$ & $54.4 \%$ & $37.2 \%$ \\
Q13 & $50 \%$ & $39.5 \%$ & $24.6 \%$ & $62.8 \%$ \\
Q14 & $65.6 \%$ & $65.1 \%$ & $56.1 \%$ & $50 \%$ \\
Q15 & $68.8 \%$ & $45.7 \%$ & $49.1 \%$ & $42.7 \%$ \\
Q16 & $62.5 \%$ & $42.6 \%$ & $31.6 \%$ & $75.7 \%$ \\
Q17 & $78.1 \%$ & $73.6 \%$ & $78.9 \%$ & $38.1 \%$ \\
Q18 & $31.3 \%$ & $42.6 \%$ & $31.6 \%$ & $66.5 \%$ \\
Q19 & $65.6 \%$ & $65.9 \%$ & $68.4 \%$ & $72.5 \%$ \\
\hline
\end{tabular}

As showcased in Table 3, it is apparent that students with the highest marks (14-27) recognized the importance of idioms more than students with lower marks (7-13 and 0-6), as those students have more positive attitudes toward all of the survey items related to the importance of idioms (Q1 to Q8). Specifically, those students realized more than students with lower knowledge of idioms that idioms are important for learners and that they should be included in language curricula. Also, they agreed more than students with lower knowledge of idioms that it is necessary for English language learners to have knowledge about idioms. Furthermore, they had more positive attitudes toward the importance of idioms and its link to frequency, figurativeness, and culture than students with lower knowledge of idioms. However, the majority of these observed differences in the 
responses across participants with different knowledge of idioms were not significant $(p>0.05)$. There was a statistically significant difference in the responses of Q2 (English language learners should have knowledge about idioms) among participants with different knowledge of idioms $(p=0.018)$. In particular, the results of the pairwise comparisons indicated that students with the lowest marks (0-6) had agreed statistically significantly less to Q2 than students with the highest marks (14-27) $(M=4.25$ for $0-6, M=4.28$ for $14-27, p=0.022)$; there was no statistically significant difference in responses of Q2 between knowledge of idioms $0-6$ and 7-13 ( $p=$ $0.596)$, and between knowledge of idioms 7-13 and 14-27 $(p=0.098)$.

As indicated in Table 3, students with the highest marks (14-27) agreed less than students with lower marks (7-13 and 0-6) with regard to all of the survey items related to the difficulties of idioms (Q9 to Q14). Students with lowest marks (0-6) agreed more than students with better knowledge of idioms that idioms are difficult. They recognized that idioms are challenging. They attributed the difficulty of idioms to frequency and familiarity as well as other factors like figurative meaning, lack of L1 equivalent, and the need for cultural and historical knowledge. Although students with the lowest marks (0-6) agreed more than students with better knowledge of idioms on these sources of difficulties, the difference in the responses was not significantly significant $(p>0.05)$. There was a statistically significant difference in the responses of Q12 (Idioms are difficult because they are hard to use in contexts) among participants with different knowledge of idioms ( $p=$ 0.002). In particular, the results of the pairwise comparisons indicated that students with the highest marks (14$27)$ had agreed statistically significantly less to Q12 than students with the lowest marks $(0-6)(M=3.34$ for $0-6$, $M=2.65$ for $14-27, p=0.008)$ and people with the middle marks $(7-13)(M=3.16$ for $7-13, M=2.65$ for 14 $27, p=0.007)$; there was no statistically significant difference in responses of Q12 between knowledge of idioms $0-6$ and $7-13(p=1.000)$.

As a strategy, students with different knowledge of idioms agreed almost equally about the use of contextualization to learn idioms. Students with low marks preferred to use key words to learn idioms whereas students with high marks preferred to learn idioms through context. These responses; however, did not yield a significant difference $(p>0.05)$. There was a statistically significant difference in the responses to Q15 (I rely on L1 to learn idioms i.e. through L1 translation) among participants with different knowledge of idioms $(p=$ 0.002). In particular, the results of the pairwise comparisons indicated that people with the highest marks (14-27) had agreed statistically significantly less to Q15 than people with the lowest marks $(0-6)(M=3.72$ for $0-6, M=$ 2.61 for $14-27, p=0.000)$ and people with the middle marks $(7-13)(M=3.16$ for $7-13, M=2.61$ for $14-27, p=$ $0.015)$; there was no statistically significant difference in responses of Q12 between knowledge of idioms 0-6 and 7-13 $(p=0.053)$. As a learning strategy, L1 translation is less preferred by students with good knowledge of idioms than for students with low knowledge of idioms.

\subsection{Limitations}

The primary limitation of the present study is that it was a single-gender study. Hence, generalizations to the opposite gender are limited. This, coupled with the use of one local college, constitutes another major limitation. Data from more than one local college and from both genders will result in a better representation.

\section{Conclusion and Recommendations}

The study investigated whether there is an influence of preexisting idiomatic knowledge on EFL college students' attitudes toward (1) the importance of idiom learning, (2) the difficulties of idiom learning, and (3) strategies for learning idioms. From the present study, we conclude that participants had positive attitudes for the subscales. In particular, participants who achieved the highest marks recognized the importance of idioms more than participants with low marks. Additionally, participants who achieved the lowest marks in the idiomatic knowledge test had statistically more positive attitudes toward the difficulties of idiom learning. Therefore, they are aware that idioms are difficult to learn. They attributed the difficulty of idioms to frequency and familiarity, as well as factors like figurative meaning, lack of L1 equivalent, and cultural and historical knowledge. As a learning strategy, L1 translation was preferred by participants with low knowledge of idioms. Also, they preferred to use keywords to learn idioms, whereas participants with good knowledge of idioms preferred to learn idioms through context.

Based on the findings of the current study, EFL instructors are recommended to use L1 translation and key words to teach students idioms if their students do not have good preexisting knowledge of idioms. However, they are recommended to use contextualization with students who already have good knowledge of idioms. Furthermore, EFL instructors should make students aware of any potential negative transfer as a result of the use of $\mathrm{L} 1$.

\section{References}

Abel, B. (2003). English idioms in first language and second language lexicon: A dual representation approach. Second Language Research, 19(4), 329-358. https://doi.org/10.1191/0267658303sr226oa 
Adkins, P. G. (1968). Teaching idioms and figures of speech to non-native speakers. Modern Language Journal, 52(3), 148-152. https://doi.org/10.1111/j.1540-4781.1968.tb01884.x

Al-Houti, S. K. \& Aldaihani, S. M. (2018). Letting the cat out of the bag: EFL college students' attitudes towards learning English idioms. International Journal of Higher Education, 7(1), 140-150. https://doi.org/10.5430/ijhe.v7n1p140

Al-Houti, S. K. \& Aldaihani, S. M. (2020). Learners in a tight corner: An investigation of figurative idiomatic competence and learner-related factors. English Language Teaching, 13(4), 76-85. https://doi.org/10.5539/elt.v13n4p76

Al-Kadi, A. (2015). Towards idiomatic competence of Yemeni EFL undergraduates. Journal of Language Teaching and Research, 6(3), 513-523. https://doi.org/10.17507/jltr.0603.06

Al-Khawaldeh, N., Jaradat, A., Al-Momani, H. \& Bani-Khair, B. (2016). Figurative idiomatic language: Strategies and difficulties of understanding English idioms. International Journal of Applied Linguistics \& English Literature, 5(6), 119-133. https://doi.org/10.7575/aiac.ijalel.v.5n.6p.119

Aljabri, S. (2013). EFL students' judgement of English idiom familiarity and transparency. Journal of Language Teaching and Research, 4(4), 662-669. https://doi.org/10.4304/j1tr.4.4.662-669

Andreou, G. \& Galantomos, L. (2007). Designing a conceptual syllabus for teaching metaphors and idioms in a foreign language context. Porta Linguarum, 9, 67-77.

Bachman, L. F. (1990). Fundamental considerations in language testing. Oxford: Oxford University Press.

Boers, F., \& Demecheleer, M. (2001). Measuring the impact of cross-cultural differences on learners' comprehension of imageable idioms. ELT Journal, 55(3), 255-262. https://doi.org/10.1093/elt/55.3.255

Boers, F., Demecheleer, M., \& Eyckmans, J. (2004). Cross- cultural variation as a variable in comprehending and remembering figurative idioms. European Journal of English Studies 8(3), 375-388. https://doi.org/10.1080/1382557042000277449

Boers, F., Eyckmans, J., Kappel, J., Stengers, H., \& Demecheleer, M. (2006). Formulaic sequences and perceived oral proficiency: Putting a lexical approach to the test. Language Teaching Research, 10(3), 245261. https://doi.org/10.1191/13621688061r195oa

Boers, F., Eyckmans, J., \& Stengers, H. (2007). Presenting figurative idioms with touch of etymology: More than mere mnemonics? Language Teaching Research 11(1), 43-62.

Boers, F., Lindstromberg, S., Littlemore, J., Stengers, H., \& Eyckmans, J. (2008). Variables in the mnemonic effectiveness of pictorial elucidation. In F. Boers \& S. Lindstromberg (Eds.), Cognitive linguistics approaches to teaching vocabulary and phraseology (pp. 189-216). Mouton de Gruyter.

Boers, F., Piquer Píriz, A.M., Stengers, H., \& Eyckmans, J. (2009). Does pictorial elucidation foster recollection of idioms? Language Teaching Researches 13(4), 367-382.

Bolinger, D. (1975). Aspects of language. Harcourt Brace Jovanovich.

Brown, H. (2001). Teaching by principles: An interactive approach to language pedagogy. Pearson Education Company.

Bulut, T. \& Çelik-Yazici, Y. (2004). Idiom processing in L2: Through rose-colored glasses. The Reading Matrix, 4, 105-116.

Cain, K. Oakhill, J. \& Lemmon, K. (2005). The relation between childrens' reading comprehension level and their comprehension of idioms. Journal of Experimental Child Psychology, 90(1), 65-87. https://doi.org/10.1016/j.jecp.2004.09.003

Can, N. (2011). A proverb learned is a proverb earned: Future English teachers' experiences of learning English proverbs in Anatolian Teacher Training High School in Turkey. (Unpublished master thesis). Middle East Technical University, Ankara.

Cooper, T. C. (1998). Teaching idioms. Foreign Language Annals, 31(2), $255-266$. https://doi.org/10.1111/j.1944-9720.1998.tb00572.x

Cooper, T. C. (1999). Processing of idioms by L2 learners of English. TESOL Quarterly, 33(2), $233-262$. https://doi.org/10.2307/3587719

Cowie, A. \& Mackin, R. (1975). Oxford dictionary of current idiomatic English, volume I. Oxford University Press.

Cronk, B. C. \& Schweigert, W. A. (1992). The comprehension of idioms: The effects of familiarity, literalness, and usage. Applied Psycholinguistics, 13(2), 131-146. https://doi.org/10.1017/S0142716400005531

Cronk, B. C. Lima, S. D. \& Schweigert, W. A. (1993). Idioms in sentences: Effects of frequency, literalness, and familiarity. Journal of Psycholinguistic Research, 22, 59-82. https://doi.org/10.1007/BF01068157

Cuadros, M. (2014). A Study on the Effectiveness of Metaphor and Cultural Awareness-Raising to the learning of Idioms in the EFL Classroom. Unpublished M.A. thesis, Spain.

Elkilic, G. (2008). Turkish students' understanding of transparent and opaque idioms in English in reading as well as speaking. Journal of Language and Linguistic Studies, 4, 27-41.

Fernando, C. (1996). Idioms and idiomaticity. Oxford University Press. 
Gibbs, R. W. (1993). Why idioms are not dead metaphors. In C. Cacciari \& P. Tabossi (Eds.), Idioms: Processing, structure, and interpretation (pp. 57-77). Lawrence Erlbaum Associates.

Glucksberg, S. \& McGlone, M. S. (2001). Understanding figurative language: From metaphors to idioms. Oxford University Press.

Guduru, R. (2012). Learning academic idioms: Some useful techniques for beginner learners. Language in India: Strength for Today and Bright Hope for Tomorrow, 12(2), 494-585.

He, Z. (1990). Knowledge of idiomacity: Evidence from idiom calquing and folk literalization. Kansas Working Papers in Linguistics, 15, 29-41.

Howarth, P. (1998). Phraseology and second language proficiency. Applied Linguistics, 19, $24-44$. https://doi.org/10.1093/applin/19.1.24

Hubers, F. Cucchiarini, C. Strik, H. \& Dijkstra, T. (2019). Normative data of Dutch idiomatic expressions: Subjective judgements you can bank on. Frontiers in Psychology, 10, 1-15. https://doi.org/10.3389/fpsyg.2019.01075

Hussein, R., Khanji, R., \& Makhzoomy, K. (2000). The acquisition of idioms: Transfer or what? Journal of King Saud University, 12(1), 23-34.

Irujo, S. (1984). The effect of transfer on the acquisition of idioms in a second language. Master's Research Paper. Boston: Boston University.

Irujo, S. (1986a). Don't put your leg in your mouth: Transfer in the acquisition of idioms in a second language. TESOL Quarterly, 20(2), 287-304. https://doi.org/10.2307/3586545

Irujo, S. (1986b). A piece of cake: Learning and teaching idioms. ELT Journal, 40(3), $236-242$. https://doi.org/10.1093/elt/40.3.236

Irujo, S. (1993). Steering clear: Avoidance in the production of idioms. International Review of Applied Linguistics in Language Teaching, 31(3), 205-219. https://doi.org/10.1515/iral.1993.31.3.205

Katsarou, E. (2011). The identification and comprehension of L2 idioms during reading: Implications for vocabulary teaching in the foreign language classroom. Lambert Academic Publishing.

Katz, J. \& Postal, P. (1963). The semantic interpretation of idioms and sentences containing them. MIT Research Laboratory of Electronic Quarterly Progress Report, 70, 275-282.

Laufer, B. (2000). Avoidance of idioms in a second language: The effect of L1-L2 degree of similarity. Studia Linguistica, 54(2), 186-196. https://doi.org/10.1111/1467-9582.00059

Levorato, M. (1993). The acquisition of idioms and the development of figurative competence. In C. Cacciaria and P. Tabossi (Eds.), Idioms: Processing, structure, and interpretation (pp. 101-128). Lawrence Erlbaum Associates.

Liontas, J. I. (1999). Developing a pragmatic methodology of idiomaticity: The comprehension and interpretation of $S L$ vivid phrasal idioms during reading. (Unpublished doctoral dissertation). The University of Arizona, Tucson, AZ.

Liontas, J. I. (2001). That's all Greek to me! The comprehension and interpretation of Modern Greek phrasal idioms. The Reading Matrix: An International Online Journal, 1(1), 1-32.

Liontas, J. (2002a). Context and idiom understanding in second languages. EUROSLA Yearbook, 2(1),155-185.

Liontas, J. I. (2002b). Exploring second language learners' notions of idiomaticity. System, 30, $289-311$.

Liontas, J. I. (2003). Killing two birds with one stone: Understanding Spanish VP idioms in and out of context. Hispania, 86(2), 289-301. https://doi.org/10.2307/20062862

Liu, D. (2003). The most frequently used spoken American English idioms: A corpus analysis and its implications. TESOL Quarterly, 37, 671-700.

Liu, D. (2008). Idioms: Descriptions, comprehension, acquisition, and pedagogy. Routledge.

Makkai, A. Boatner, M. \& Gates, J. (1995). A dictionary of American idioms. Barrons' Educational Series.

Milosky, L. (1994). Nonliteral language abilities: Seeing the forest for the trees. In G. Wallach \& K. Butler, K. (Eds), Language learning disabilities in school-age children and adolescents: Some underlying principles and implications (pp. 275-303). Merrill.

Moreno, E. (2011). The role of etymology in the teaching of idioms related to colours in an L2. Porta Linguarum, $16,19-32$.

Nelson, E. (1992). Memory for metaphor by nonfluent bilinguals. Journal of Psycholinguistics Research. 21, 111-125. https://doi.org/10.1007/BF01067990

Nippold, M. (1991). Evaluating and enhancing idiom comprehension in language disordered students. Language, Speech, and Hearing Services in Schools, 22, 100-106. https://doi.org/10.1044/0161-1461.2203.100

Nippold, M. (2003). Mental imagery and idioms comprehension: A comparison of school-age children and adults. Journal of Speech, Language and Hearing Research, 46(4), 788-799.

Nordmann, E. Cleland, A. A. \& Bull, R. (2014). Familiarity breeds dissent: Reliability analyses for BritishEnglish idioms on measures of familiarity, meaning, literality and decomposability. Acta Psychologica, 146, 87-95. https://doi.org/10.1016/j.actpsy.2014.03.009 
Oppenheim, N. (2000). The importance of recurrent sequences for non-native speaker fluency and cognition. In Riggenbach, H. (Ed.), Perspectives on fluency (pp. 220-240). University of Michigan Press.

Ovando, C. T. \& Collier, V. P. (1985). Bilingual and ESL classroom: Teaching in multicultural contexts. New York: McGraw-Hill Book Company.

Pawley, A. \& Syder, F. H. (1983). Two puzzles for linguistic theory: Nativelike selection and nativelike fluency. In J. C. Richards \& R. W. Schmidt (Eds.), Language and communication (pp. 191-226). Longman.

Pitzl, M-L. (2016). World Englishes and creative idioms in English as a lingua franca. World Englishes, 35(2), 293-309. https://doi.org/10.1111/weng.12196

Pollio, H. R., Barlow, J. M., Fine, H. K., \& Pollio, M. R. (1977). Psychology and the poetics of growth. Erlbaum.

Popiel, S. \& McRae, K. (1988). The figurative and literal senses of idioms or all idioms are not used equally. Journal of Psycholinguistic Research, 17, 475-487. https://doi.org/10.1007/BF01067912

Prodromou, L. (2003). Idiomaticity and the non-native speaker. English Today, 19(2), 42-48. https://doi.org/10.1017/S0266078403002086

Saleh, N., \& Zakaria, N. (2013). Investigating the difficulties faced in understanding, and strategies used in processing English idiom by the Libyan students. International Journal of English Language and Translation Studies, 1(2), 69-90.

Schmitt, N. (2000). Vocabulary in language teaching. Cambridge University Press.

Shirazi, M. \& Talebinezhad, M. (2013). Developing intermediate EFL learners' metaphorical competence through exposure. Theory and Practice in Language Studies, 3(1), 135-141. https://doi.org/10.4304/tpls.3.1.135-141

Steinel, M., Hulstijn, J. \& Steinel, W. (2007). Second language idiom learning in a paired associate paradigm: Effects of direction of learning, direction of testing, idiom imageability and idiom transparency. Studies in Second Language Acquisition, 29, 449-484. https://doi.org/10.1017/S0272263107070271

Strässler, J. (1982). Idioms in English: A pragmatic analysis. Günter Narr.

Sugano, M. (1981). The idiom in Spanish language teaching. Modern Language Journal, 65, 59-66. https://doi.org/10.1111/j.1540-4781.1981.tb00955.x

Titone, D. A \& Connine, C. M. (1994). Descriptive norms for 171 idiomatic expressions: Familiarity, compositionality, predictability, and literality. Metaphor and Symbolic Activity, 9(4), 247-270. https://doi.org/10.1207/s15327868ms0904_1

Tran, T. (2013). Figurative idiomatic competence: An analysis of EFL learners in Vietnam. Language Education in Asia, 4(1), 23-38. https://doi.org/10.5746/LEiA/13/V4/I1/A3/Tran

Thiel, F. (1979). The case for idioms. Die Unterrichtspraxis, 12, 21-24. https://doi.org/10.2307/3529399

Viteli, J. (1989). Learning styles and individual differences in learning English idioms via computer assisted language learning in English as a second language. Paper presented at the annual meeting of European association of research on learning and instruction, Madrid, Spain.

Weinert, R. (1995). The role of formulaic language in second language acquisitions. Applied Linguistics 16(2), 180-205. https://doi.org/10.1093/applin/16.2.180

Wray, A. (2000). Formulaic sequences in second language teaching: Principle and practice. Applied Linguistics, 21(3), 463-489. https://doi.org/10.1093/applin/21.4.463

Wray, A. (2002). Formulaic language and the lexicon. Cambridge: University Press.

Yorio, C. A. (1980). Conventionalized language forms and the development of communicative competence. TESOL Quarterly, 14(4), 433-442. https://doi.org/10.2307/3586232

Yorio, C. (1989). Idiomaticity as an indicator of second language proficiency. In K. Hyltenstam and L. Obler (Eds.), Bilingualism across the lifespan: Aspects of acquisition, maturity, and loss (pp. 55-72). Cambridge University Press. 